\title{
Evidencing creativity and curiosity in IB schools
}

\author{
Dr Sarah Richardson \\ Australian Council for Educational Research \\ Dr Sladana Krstic \\ Australian Council for Educational Research \\ https://doi.org/10.37517/978-1-74286-638-3_7
}

Dr Sarah Richardson is a passionate researcher, educator and writer. She has been working in the education sector for 28 years as a teacher, lecturer, researcher and research director. Sarah is the Research Director of the Surveys and International Assessments team in the Australian Council for Educational Research (ACER). She returned to Australia in April 2021 having been Deputy CEO and Research Director of ACER UK, and previously Research Director of ACER India. Sarah has a PhD in education and politics from the University of Melbourne, a Master's Degree in International Relations from the University of Amsterdam and a Bachelor's Degree in Human Geography from the University of Liverpool.

Dr Sladana Krstic leads the psychometrics and research team for ACER UK. She has worked on a variety of projects, including the Scottish National Standardised Assessments; the British Council's English Impact project; the International Baccalaureate programmes; and the Royal Society of Chemistry evaluation programme. Sladana has a Doctorate in Education and is an expert researcher in quantitative and qualitative methodology, data analysis, sampling designs, and questionnaire development. She is currently engaged in a ground-breaking research project for the International Baccalaureate Organisation and the Jacobs Foundation on curiosity, creativity and learning.

\section{Abstract}

There is growing recognition of the importance of learners gaining transversal or 21st-century attributes in order to thrive in the contemporary world. This poses a number of challenges for educators. First, to what extent are transversal attributes innate, or do they include a combination of traits and skills? Second, what can teachers do to help nurture these attributes in learners? Third, how can the existence or strengthening of attributes be recognised? In this paper, we draw on work that we are doing for the International Baccalaureate Organisation to define conceptual frameworks for creativity and curiosity. Our goal is to enable learners to evidence achievement in each of these attributes, and for teachers to be able to recognise it. The frameworks draw on extensive scholarly literature to define the core components of both curiosity and creativity and the skills that are inherent in each one. This is the first step towards the development of a 'transversal résumé' that will allow learner achievement to be recorded. This includes a focus on the extent to which schools and teachers can provide learners with opportunities to gain, practice or enhance the skills that contribute to transversal attributes and a scaffold that enables learners to reflect on the extent to which they have evidenced creativity or curiosity in sustained pieces of work. The paper raises some key questions that have arisen as we have grappled with both conceptual and practical issues in this project. These provide valuable insights into the nurturing of transversal attributes, and the implications for educational professionals. 


\section{Introduction}

There is a growing focus in education systems around the world about the importance of transversal attributes. Educational professionals are increasingly acknowledging that for learners to thrive in their future lives, they need to be equipped with a good balance of academic competencies and transversal attributes. How this can be achieved is, however, much less clear cut. There is no consensus about how to refer to these attributes - with alternatives being '21st century', 'holistic', 'generic', 'soft' and 'multi-disciplinary'. There is no consensus on whether these are even attributes at all, with some suggesting that they are skills.

In this context, the Australian Council for Educational Research (ACER) was approached by the International Baccalaureate Organisation (IBO) to develop a way to evidence two transversal attributes across its educational programmes. Generously funded by the Jacob's Foundation, ACER has been working closely with the International Baccalaureate (IB) since August 2020 to develop frameworks for curiosity and creativity. Our approach builds on previous work to develop frameworks in other transversal areas such as collaboration (Scoular et al., 2020) and critical thinking (Heard et al., 2020).

In this paper, we provide an overview of the process followed, an insight into the frameworks developed and a recognition of some of the significant debates that have made this work both intellectually and practically challenging.

\section{Background and context}

This work was informed by a number of key parameters. First, it needed to be usable across all IB programmes: the Primary Years Programme (PYP); the Middle Years Programme (MYP), the Diploma Programme (DP) and the Career-Related Programme (CP). This meant it had to be applicable for learners aged 3 to 19 years. Second, it needed to be relevant for all schools implementing IB programmes, wherever they are in the world. Third, it should enable schools to evidence learner achievement and progress without assigning grades or using formal assessment tools.

IB programmes have a foundational core philosophy, yet each retains a distinct focus and purpose. Broadly, IB programmes focus on holistic education that:

... encourage both personal development and academic achievement challenging students to think critically, to ask the right questions and think across disciplines. An IB education also fosters diversity, curiosity and a healthy appetite for learning (International Baccalaureate Organisation, n.d.).

Schools that wish to provide IB programmes first need to be authorised to do so. Some schools offer just one programme and others more. As of May 2021, there are 5500 IB World Schools in 159 countries (International Baccalaureate Organisation, 2021). While diverse in nature, each programme is supported by the IB Learner Profile, which identifies a set of attributes that IB learners strive to have. These include being reflective, open-minded, thinkers and communicators. (International Baccalaureate Organisation, 2013). Another core element of all IB programmes is the focus on inquiry-based learning. While neither creativity nor curiosity are explicitly mentioned as attributes in the Learner Profile, they are key elements of much of the IB's philosophy.

While many education systems and programmes reference transversal attributes, it is common for this to be superficial, with little follow-through to the level of the curriculum, to school leadership, to teacher professional learning or to pedagogy. In this project with the IBO, ACER is focusing on developing resources that enable creativity and curiosity to be supported, that guide teachers in helping learners gain the skills that underlie these attributes and that enable achievement to be recorded. 
In parallel, the Oxford University Centre for Educational Assessment is undertaking a project to gather samples of promising classroom practices where learners are provided with opportunities to gain or practice either creativity or curiosity. The two projects have worked closely together, with efforts to optimise synergies between them. Inevitably, both projects have been impacted by the Covid-19 pandemic and required adaptations to methodologies.

\section{Methodology}

Before a transversal attribute can be evidenced, it first needs to be defined. It is common practice to start with the development of a framework to propose a working definition and then to break down the overall construct into what are commonly referred to as 'strands' - overarching conceptual categories for framing the skills and knowledge associated with the construct. These are amenable to instruction, provide evidence of the construct, and can potentially be assessed. The strands are subsequently broken down into 'aspects' which are specific content categories within a strand.

As with many transversal domains, there is extensive scholarly literature about both creativity and curiosity. However, it can be extremely challenging to take something that may be esoteric and theoretical, or based on psychological and neuroscientific processes that are intangible, and define it in a way that is suitable for an educational context. Accordingly, this project started with a global three-day virtual symposium that brought together scholars with expertise on either curiosity or creativity, as well as educational professionals from IB schools around the world.

Through a series of facilitated discussions and reflections, the symposium was able to set a clear direction for the subsequent stages of the project. This included identifying three tensions that are often absent from the literature on transversal attributes in education. First, unless schools provide a suitably enabling environment for the practice of transversal attributes, it is very difficult for learners themselves to demonstrate the development of these. Hence, part of the evidencing of transversal attributes is for schools and teachers to demonstrate that they provide optimal conditions for transversal attributes to be nurtured.

Second, teachers play a key role in assisting learners to enhance transversal attributes and their corresponding skills, including through modelling these themselves. Given that emotions such as disappointment and frustration are inevitable parts of many transversal attributes, this means that teachers need to be provided with an environment in which learners are allowed to fail. Third, efforts to evaluate, measure or assess transversal attributes carry the inherent risk of reducing what is recognised as their expression, hence contradicting the nurturing of the attributes. In this project, we have steered clear of the terms 'measurement' or 'assessment', instead referring to these as 'evidencing', partly as an acknowledgement of this third tension.

The symposium was the starting point for work on this project. It was followed by three key steps, the third of which remains in progress at the time of writing. First, two teams of ACER researchers carried out an in-depth literature review of scholarly work on either creativity or curiosity. These literature reviews drew on hundreds of journal articles and provided a foundation for the development of frameworks. Second, the literature reviews were handed over to two teams of ACER framework experts, all of whom had previously worked on the development of frameworks for transversal domains. They drew on the literature to arrive at working definitions of each construct and an appropriate set of strands and aspects.

In the third step, ACER researchers commenced an extended period of consultation. This has involved scholarly experts from the initial symposium, IB curriculum and subject managers from each IB programme and senior IB managers. The next stage - somewhat delayed and requiring methodological workarounds due to the impact of the COVID-19 pandemic on schools - is to consult with teachers and programme coordinators in IB schools in all parts of the world. This paper 
provides an insight into the frameworks as they exist in June 2021. It is important to note that these are in draft form and may change substantially when consultations have concluded.

\section{Draft frameworks}

For each construct of curiosity and creativity, the first element of the framework is the definition. This ensures both a sound evidentiary basis as well as a consideration of factors that are amenable to teaching and learning. These definitions are then further elaborated using strands and aspects.

For creativity, the working definition focuses the attention on working with things, ideas, or people - or any combination of the three - in a purposeful and directed way, taking account of real-world constraints. The outcomes or 'products' of creativity are defined as having the key characteristics of novelty and usefulness. Beyond generating these, our definition posits that creativity involves openness to the exploration of ideas, including through the examination of these from different perspectives, and the synthesis of different ideas.

Creativity is a material, mental and/or social process that leads to the production of novel and useful ideas, approaches and solutions. It involves the exploration, generation and evaluation of both problems and ideas, made possible through divergent, experimental and convergent thinking. (Scoular \& Ramalingam, 2021).

The strands and aspects of creativity are defined as: problem finding (comprising discoveryoriented behaviour and formulating a problem); generating ideas (comprising fluency, flexibility and experimentation); and quality of ideas (comprising originality, fitness for purpose and elaboration).

For curiosity, the working definition focuses the attention on curiosity as an attribute that fosters deep and lifelong learning. It refers to a meaningful gap in which one addresses a substantive task that facilitates richer, deeper or broader conceptual understanding. Curiosity is regarded as an intrinsic part of a process of self-motivated development of knowledge and understanding. This includes many elements that are already emphasised in IB programmes, including inquiry skills, critical thinking, open-mindedness, risk taking, self-efficacy and reflection. Curiosity provides the incentive and reward for seeking new knowledge and understanding, requiring other skills to ensure that this learning is rich, sustained and productive.

Curiosity involves the recognition of a meaningful gap in one's knowledge or understanding, the desire to fill that gap and the motivation and intrinsic satisfaction of doing so (Heard \& Anderson, 2021).

The strands and aspects of curiosity are defined as: focusing curiosity (comprising engaging with and exploring conceptual conflicts, enhancing motivation and refining questions of value) and resolving knowledge gaps (comprising exploring answers and thinking critically, sustaining effort and evaluating learning).

\section{Evidencing and enabling environments}

Frameworks developed for cognitive skills, such as mathematics or reading, would normally specify different levels of competence or achievement, with the expectation that these are subsequently validated by the collection of assessment data. For transversal attributes, however, very little is known about how these are developed and this makes the development of a progression challenging. During the commencement of this project with the global symposium, participants cautioned against a reductionist approach that would define a construct narrowly enough to allow it to be assessed, hence squeezing the inherent freedom and space to explore out of these elements. 
At the same time, the IBO is keen to be able to develop something that enables learners' transversal attributes to be summarised, albeit avoiding 'grading' them.

In this context, and after much debate and consideration, our approach has been to consider three elements: 1) the environment in which learning takes place (for schools); 2 ) opportunities to gain, practice or enhance the skills that are inherent within transversal attributes (for teachers); and 3 ) a scaffold that enables learners to reflect on the extent to which they have evidenced creativity or curiosity in sustained pieces of work (for learners). The underlying philosophy to our approach is a recognition that schools and teachers have a responsibility to provide the conditions in which learners have the time, space, permission and learning opportunities to be able to be creative and to be curious. To achieve these three elements, we are planning to develop the following.

\section{For schools: A framework for reflection upon the environment for learning}

A framework will help schools to reflect on the extent to which they provide enabling environments for creativity and curiosity. For elements such as 'task opportunities' and 'access to resources', we plan to provide schools with a number of 'temperatures' or 'levels' for their practices to be evaluated against. For example, schools that provide comprehensive or minimal opportunities for learners to be curious could recognise themselves as those in which:

Comprehensive - Learners are given open tasks with clear guidelines that focus on promoting curiosity-driven learning; sufficient time is allowed for investigations and reflections; and curiosity not compromised by other task purposes.

Minimal - Any opportunities to demonstrate curiosity are largely prescribed or predictable, or may be missing entirely (Heard \& Anderson, 2021).

\section{For teachers: Suggested approaches to support learners in gaining, practicing or enhancing the skills within transversal attributes}

We plan to develop suggestions for teachers around how they can utilise classroom activities to support learners to gain, strengthen or practice the skills that facilitate creativity or curiosity. For example, in order to support learners to practice refining questions of value (an important aspect within curiosity) teachers may wish to focus on helping them to develop 'high-value questions that are likely to challenge understanding and lead to significant new insights' (Heard \& Anderson, 2021). This may include elements such as the ability to distinguish between questions that address confusion or gaps in understanding, and those that might be secondary or consequential questions.

\section{For learners: A structure that facilitates reflection}

Learners will be facilitated to reflect (with support from teachers where required) on the extent to which their curiosity or creativity is embodied in sustained pieces of work using a structure. We consider that the best opportunities for this to occur would be in the extended culminating project in each programme, including the 'Exhibition' in PYP and 'Extended essay' in DP. For example, a learner may reflect on the extent to which they have engaged with, and explored, conceptual conflicts. This could involve identifying the extent to which they have practiced in-depth, open and imaginative exploration of stimuli; identified gaps, inconsistencies or contradictions from a range of perspectives and possibilities; and made connections with a broad range of ideas. 


\section{Conclusion}

While this project remains in progress, with consultations with schools still to be undertaken, it has already raised some key questions around transversal attributes and their incorporation into educational settings. First, it has identified the importance of schools providing an enabling environment in which learners - and teachers - are free to be creative and curious. Second, it has identified the need to consider the ways in which teachers can help learners acquire, practice and strengthen the skills that contribute to creativity and curiosity. Third, it has highlighted the challenges involved in evidencing creativity and curiosity, and the desirability of engaging learners in reflecting on their own achievement.

While the project focuses on two specific transversal attributes, we feel that these issues are equally important considerations for other transversal attributes. Education sectors are becoming increasingly aware of the need to prepare learners for their future lives, ones that will demand a wide variety of attributes, skills and knowledge. Unpacking, defining and operationalising transversal attributes requires critical evaluation of the implications for educational institutions and professionals. This project makes an important contribution to that debate.

The authors would like to thank the Jacobs Foundation and International Baccalaureate Organisation for funding this project. We would also like to recognise the contributions of our current and former ACER colleagues Prue Anderson, Anit Cherian, Laura Good, Jonathan Heard, Brendan McGinley, Abigail Middel, Dara Ramalingam, Claire Scoular, Shani Sneidze-Gregory, Jennifer Star and Anaghaa Wagh.

\section{References}

Heard, J. \& Anderson, P. (2021). DRAFT curiosity combined preamble, framework and progression [Manuscript in preparation]. Australian Council for Educational Research.

Heard J., Scoular, C., Duckworth, D., Ramalingam, D., \& Teo, I. (2020). Critical thinking: Skill development framework. Australian Council for Educational Research. https://research.acer.edu. au/ar_misc/41

International Baccalaureate Organisation (nd). Programmes. https://www.ibo.org/programmes/

International Baccalaureate Organisation (2013). IB learner profile. https://www.ibo.org/ contentassets/fd82f70643ef4086b7d3f292cc214962/learner-profile-en.pdf

International Baccalaureate Organisation (2021). Facts and figures. https://www.ibo.org/about-theib/facts-and-figures/

Scoular, C. \& Ramalingam, D. (2021). DRAFT Creativity combined preamble, framework and progression [Manuscript in preparation]. Australian Council for Educational Research.

Scoular, C., Duckworth, D., Heard, J., \& Ramalingam, D. (2020). Collaboration: Skill development framework. Australian Council for Educational Research. https://research/acer/edu.au/ar_misc/42 